\title{
Exploring of Potential of Cloud Computing for Small and Medium Enterprises
}

\author{
S Kamarudin *1, A H A Khalili², Z F A Aziz ${ }^{3}$, K A Kamarudin ${ }^{4}$, A N A Wahab \\ ${ }^{1}$ Faculty of Computer Science and Information Technology, Universiti Putra \\ Malaysia, 43400 UPM Serdang, Selangor, Malaysia. \\ ${ }^{2}$ Faculty of Humanities, Management and Science, Universiti Putra Malaysia Bintulu \\ Sarawak Campus P.O. Box 396, Nyabau Road, Bintulu, Sarawak, Malaysia. \\ ${ }^{3}$ Faculty of Agriculture Science and Forestry, Universiti Putra Malaysia Bintulu \\ Sarawak Campus P.O. Box 396, Nyabau Road, Bintulu, Sarawak, Malaysia. \\ ${ }^{4}$ Faculty of Business, University of Wollongong in Dubai, Dubai Knowledge Park, \\ Dubai, United Arab Emirates. \\ ${ }^{5}$ Faculty of Information Science and Technology, Universiti Kebangsaan Malaysia, \\ 43400 Bangi, Selangor, Malaysia.
}

E-mail: shafinah@upm.edu.my ${ }^{1}$, alfanhidayat@upm.edu.my², zakry

fitri@upm.edu.my ${ }^{3}$,KhairulKamarudin@uowdubai.ac.ae ${ }^{4}$, anaw@ukm.edu.my ${ }^{5}$

Submitted: 26 Jan 2022, revised: 22 Feb 2022, accepted: 24 Feb 2022

\begin{abstract}
Business activities such as human resources management, payroll, finance, and accounting are crucial for Small and Medium Enterprises (SMEs). Therefore, SMEs are expected to gain benefits from technologies such as cloud computing. The migration from current business practices to cloud computing amongst SME entrepreneurs remains a challenge. Therefore, this study presents a short review of cloud computing concepts, the characteristics, types of cloud computing service models, and also cloud computing deployment models. This study highlights the benefits and challenges faced by SMEs entrepreneurs in adopting cloud computing. Also, this study explores the existing cloud computing services provided for SMEs. The present study aims to provide a deeper knowledge and understanding of the potential for cloud computing to be applied in supporting SMEs in managing their business activities.
\end{abstract}

Keywords: cloud computing, IT adoption, small and medium enterprises, benefits and challenges 


\section{Introduction}

The outbreak of the Coronavirus (COVID-19) Pandemic, which started in November 2019 has led the world to a far worse economic disaster in comparison to the 2008-2009 global financial crisis. The COVID-19 pandemic is a worldwide disaster not limited to any continent, country, and locality. In general, small and medium enterprises (SMEs) contribute to over 90 percent of economic activities, create more than half of all employment worldwide, and contribute more than 40 percent of gross domestic product (GPD) in developing countries. Due to travel and movement restrictions imposed in most countries to control the spreading of Covid19, industry sectors, including SMEs, face a tremendous loss [1]. Additionally, SMEs faced a variety of difficulties, including power shortages, a constraint of funding, a lack of management skills and competencies, a lack of information, and corruption [2].

During this critical period, ICT, including cloud computing technology, offers SMEs opportunities and alternatives to manage their businesses in times of crisis. Cloud computing is a concept of IT service model that can provide computing services over a network [3]. The use of cloud computing technologies can reduce computing costs. It is estimated that in 2020, 78 percent of SMEs would have implemented some form of cloud computing technology [4].

This study aims at elaborating the concepts which collectively comprise cloud computing. Further, this study clarifies and explores the types of cloud computing. The present study addresses the advantages of adopting cloud computing for SMEs and the problems faced by them. This research exposes the latest cloud computing services that are available to SMEs. Therefore, this research is expected to provide a better understanding and help further encourage the adoption of cloud computing amongst SMEs.

\section{Methodology}

The qualitative method was utilised for the study, including data collection, literature review, and gathering of relevant information pertaining to cloud computing knowledge. The study aimed to address the following questions:

i. What are the definitions, characteristics, and models of cloud computing?

ii. What are the benefits and challenges in implementing cloud computing for SMEs?

iii. What are available cloud computing services are available for SMEs?

iv. How do these cloud computing services help SMEs in managing their business operations?

Based on these questions, keywords were applied to obtain relevant literature on the definition of cloud computing, characteristics, and cloud models. Furthermore, the literature search was carried out based on SMEs' benefits and challenges in implementing cloud computing. This information was listed in table format. Regardless, the most crucial part was in revealing the existing cloud computing services available for SMEs. The approach used in this process was through the observation, identification, and categorizing of the current cloud computing services which were available online. Thus it was critical to comprehend the available cloud computing services in order to determine cloud computing's potential for application in SMEs.

\section{Background}

\subsection{Definition of Cloud Computing}

The history of modern computers began in 1941, since then the technology related to the modern computer era has exponentially evolved. Cloud computing can be seen as a part of the evolution of modern computing. The genesis of cloud computing began in 2007. In general, cloud computing refers to a joint measure of hardware and software deployment [5].

The term 'Cloud' refers to different platforms for distributing computing services. The term 'computing' refers to delivering this computing package as a service that users can access based on their demands [6]. The majority of definitions from previous works follow this basis [7]. Cloud

\footnotetext{
Kamarudin, Khalili, Aziz, Kamarudin, Wahab (Exploring of Potential of Cloud Computing for Small and
} Medium Enterprises) 
computing is most commonly described as a model providing convenient on-demand network access to a shared pool of configurable computing resources (e.g., networks, servers, storage, applications, and services) that can be rapidly provisioned and released with minimal management effort or service provider interaction $[3,7]$.

The analysis from several studies has been conducted to address the definition of cloud computing comprehensively [5]. The terms related to cloud computing such as services, hardware, software, data, platform, pay-per-use, public, scalability, no upfront commitment, virtualisation, Service Level Agreements, deterministic performance, network or Internet, and automation were applied during the analysis. In conclusion, cloud computing can be best defined as an IT deployment model based on virtualisation. In terms of infrastructure, applications, and data, resources are deployed via the Internet as a distributed service by one or several service providers. These services are scalable on-demand and can be priced on a pay-per-use basis [5].

\subsection{Cloud Computing's Basic Characteristics}

The main characteristics of cloud computing are depicted in Figure 1[8]. A brief explanation of each characteristic is described as follows:

- On-demand self-service: Ability to automatically provide computing capability such as server time/network storage.

- Rapid elasticity: Elasticity is given to meet customer demands as cloud storage is regularly made available as if it were unlimited (may be accepted in terms of quantity and time)

- Broad access network: Cloud computing is available through a network or Internet, and it has a standard mechanism in handling heterogeneous platforms.

- Resources pooling: Multi-tenant cloud computing resources are pooled to serve numerous users. Physical and virtual resources are assigned and reassigned dynamically based on demand.

- Measured service: The provider's computing resources are pooled to serve multiple users using a multi-tenant model.

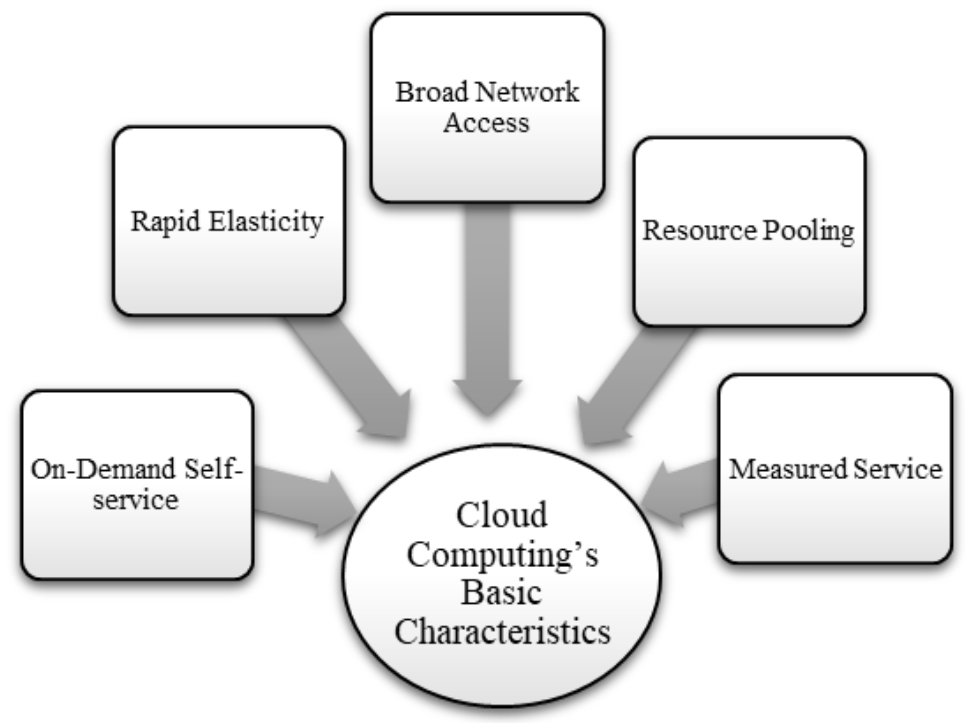

Figure 1. Cloud Computing's Basic Characteristics [8]

Based on these essential characteristics, cloud computing is made accessible via network or Internet, it has a standard mechanism for handling heterogeneous platforms, the elasticity is offered to satisfy customer demands as cloud storage is regularly made available as if it were unlimited, and cloud computing resources services are pooled to support multiple users using a multi-tenant model.

Kamarudin, Khalili, Aziz, Kamarudin, Wahab (Exploring of Potential of Cloud Computing for Small and Medium Enterprises) 


\section{Cloud Computing Services Model}

Cloud computing delivers the package or IT-related facilities depending on the client's demand. Therefore, cloud computing has several service models that help SMEs select a suitable architecture standard to be adopted. The most common service models are Software as a Service (SaaS), Infrastructure as a Service (IaaS), and Platform as a Service (PaaS). The following are brief explanations of those service models [9;10]:

\subsection{Software as a Service (SaaS)}

The following describes the SaaS model:

- SaaS provides applications distribution via the Internet browser or lightweight applications [9].

- SaaS software is purchased and installed on a personal computer, similar to a distribution model in which both vendors and service providers can access the applications.

- SaaS provides end-users to access data over a shared platform such as the Internet. It is a suitable, progressively predominant distribution model. This highlights service-oriented architecture (SOA) web services advances and novel development methodologies.

- SaaS is commonly associated with a subscription-based licensing model.

- Broadband services have been progressively available to end-users, giving them wider access to more regions worldwide [11].

- Examples: Google docs, Microsoft Office 365, Wix, and Squarespace.

\subsection{Infrasturcture as a Service (IaaS)}

The model of IaaS is outlined below:

- IaaS is a virtual environment that provides a large array of computing resources.

- IaaS typically provides data storage, virtualisation servers, computer services, and networking, usually on a pay-per-use basis, and is highly scalable.

- Businesses utilise IaaS for the following purposes: (1) testing and development, (2) web hosting, (3) storage, backup, and recovery, (4) web applications, (5) high-performance computing, and (6) big data analysis [12].

- Examples: Amazon Web Services, Microsoft Azure, Google Cloud Platform, and IBM Cloud $[9,13]$.

\subsection{Platform as a Service (PaaS)}

The PaaS model is described as follows:

- PaaS offers a set of services and workflows targeting developers, who may leverage shared tools, processes, and APIs to accelerate applications' development, testing, and deployment.

- It is a closed environment for app developers.

- Ensure that developers have immediate access to resources, adhere to certain processes, and utilise a specific array of services, while operators maintain the underlying infrastructure.

- Example: Salesforce's Heroku, Force.com, Red Hat's OpenShift.

\subsection{Cloud Computing's Deployment Model}

Three deployment models are available: public cloud, private cloud, and hybrid cloud. The deployment model is described as follows:

- Public Cloud: A cloud is deemed a public cloud when the available infrastructure for contracting comprises shared, standardised, and self-service Internet resources. 
- Private Cloud: Private clouds utilize infrastructure with cloud computing characteristics, such as virtualisation, but in the form of a private network. Private clouds have greater control over the cloud infrastructure and are installed within a company's own firewall, exclusively offered to one particular company and ideal for larger companies $[6,14,15]$.

- Hybrid Cloud: The combination of public and private clouds, allowing users to use the best finest characteristics of each.

Several studies have recommended deploying hybrid clouds to overcome issues related to privacy and security. Deploying the hybrid cloud is referred to as transferring IT services to the public cloud, while the rest is maintained internally [14].

\section{Benefits and Challenges of Cloud Computing for SMEs}

This section comprises two parts. Firstly, the benefits that SMEs could gain from adopting cloud computing in their businesses are elaborated. Next, the challenges facing cloud computing are discussed.

\subsection{Benefits of Cloud Computing for SMEs}

The benefits of cloud computing technology for SMEs can reduce computing costs, data reliability and availability, data security and protection, optimisation of time to market product or services, and work collaboration as well as flexibility $[3,6,16]$. Table 1 explains the benefits of cloud computing for SMEs.

Table 1. The Advantages of Cloud Computing Adoption for SMEs

\begin{tabular}{|c|c|}
\hline Benefits & Description \\
\hline $\begin{array}{l}\text { Reduce } \\
\text { costs }\end{array}$ & $\begin{array}{l}\text { - The third-party cloud provider can make enterprise-level technology } \\
\text { affordable and easy to adopt for SMEs clients. } \\
\text { - SMEs are capable of expanding their network capability without } \\
\text { investing in new hardware and software. } \\
\text { - Some cloud computing services provide for free } \\
\text { - Cloud computing has no physical data storage. SMEs can subscribe } \\
\text { or pay certain fees if the storage capacity reaches the maximum size } \\
\text { of cloud storage. SMEs did not have to invest in additional hardware } \\
\text { as storage. } \\
\text { - Most of the cloud computing services did not require an upfront } \\
\text { investment. } \\
\text { - Cloud computing service providers free network management - } \\
\text { responsible for monitoring, maintaining, upgrading the network. }\end{array}$ \\
\hline $\begin{array}{l}\text { Data reliability } \\
\text { availability }\end{array}$ & $\begin{array}{l}\text { - Cloud computing enables data to be stored offsite and backed up to } \\
\text { several places. As a result, all IT resources may be rapidly and } \\
\text { simply restored in the case of a server loss. } \\
\text { - Data stored in the cloud is always in the most recent version. }\end{array}$ \\
\hline $\begin{array}{l}\text { Data are secured and } \\
\text { protected }\end{array}$ & $\begin{array}{l}\text { - Since the data is stored in the cloud, SMEs reduce the data lost due to } \\
\text { major natural disasters. } \\
\text { - Data sent to the cloud is encrypted, which prevents the data from } \\
\text { being intercepted by others (unauthorised users) }\end{array}$ \\
\hline $\begin{array}{lcc}\text { Optimise } & \text { time } & \text { to } \\
\text { market } & \text { products } & \text { or } \\
\text { services } & & \end{array}$ & $\begin{array}{l}\text { - Cloud computing services can be used to cover sales, promotions, or } \\
\text { seasonality, then reduced when revenue slows. Pay based on SMEs } \\
\text { require and avoid wasting money on unused resources }\end{array}$ \\
\hline
\end{tabular}

Kamarudin, Khalili, Aziz, Kamarudin, Wahab (Exploring of Potential of Cloud Computing for Small and Medium Enterprises) 


\begin{tabular}{|c|c|}
\hline Benefits & Description \\
\hline $\begin{array}{l}\text { Work Collaboration } \\
\text { and Flexibility }\end{array}$ & $\begin{array}{l}\text { - Cloud computing able to be accessed anywhere at any time. This } \\
\text { benefit gives SMEs flexibility in performing their jobs or any tasks. } \\
\text { - Cloud computing services enable SMEs to give the right credentials } \\
\text { to their users. This ability provides employees in SMEs to } \\
\text { collaborate and work effectively from anywhere at any time. }\end{array}$ \\
\hline
\end{tabular}

Table 1 shows that SMEs can increase their network capabilities without the need for expanding to new infrastructure and software whilst minimizing computing costs. For instance, most cloud services providers did not charge for an upfront investment and payment depending on SMEs' requirements. Furthermore, cloud computing can store data offsite and backup to other locations. This feature gives SMEs flexibility in accessing data, preventing data loss, with adding security. Furthermore, SMEs can collaborate with their trading partners and stakeholders, as well as support their customers, especially for data transactions such as sales and information sharing. Due to this matter, cloud computing has now sparked significant attention as a major research topic due to its potential to serve as an enabling factor for SMEs.

\subsection{Challenges of SMEs to Adopt Cloud Computing}

Even though cloud computing benefits SMEs across a wide range of facets, several studies reveal that SMEs' are still faced with challenges in adopting cloud computing. There are four major challenges for adopting cloud computing in SMEs: data management, the background of SMEs, cloud computing technology, and expenses of SMEs, these are summarised in Table 2.

Data security is a significant challenge that must pay attention to because it includes the business profile of SMEs. Therefore, the government should be alert in the legal aspect when adopting the cloud computing system into SMEs. Besides, the government must have a strategic plan to support SMEs in terms of funds since maintaining and sustaining the cloud computing system needs a tremendous amount of money and needs workers with IT skills. Otherwise, the government should provide an excellent infrastructure to SMEs, including knowledge transfer and soft skills from the expert, instead of letting SMEs manage it alone without any guidance and guidelines. The two parties must be engaged consistently to implement the cloud computing system in SME's success. The government also needs to provide a more secure system to protect each SMEs' business profile. Besides, SMEs must be more proactive in learning new technology since cloud computing technology offers many advantages to the company in terms of managing their business.

Table 2. The challenges of Cloud Computing Adoption for SMEs

\begin{tabular}{|c|c|}
\hline Challenges & Description \\
\hline $\begin{array}{l}\text { Data } \\
\text { management }\end{array}$ & $\begin{array}{l}\text { - Issues relating to the protection, confidentiality, laws and enforcement of data } \\
\text { in SMEs }[17,18,19,20,21,23,24] \\
\text { - Lack of data control in the case of a cloud emergency, such as losing } \\
\text { customer information and data from the business profile } \\
{[17,19,20,23,25,26,27]} \\
\text { - It is crucial to consider the legal aspect of storage data outside companies } \\
\text { regarding data ownership to prevent infringement of intellectual property } \\
{[17,20,22,27,28]}\end{array}$ \\
\hline $\begin{array}{l}\text { Background of } \\
\text { SMEs }\end{array}$ & $\begin{array}{l}\text { - Inability to realise potential advantages due to a lack of technical resources, } \\
\text { which include time, infrastructure, and IT expertise [17,19,25,26,27,29,30,31] } \\
\text { - Lack of understanding and lack of awareness of cloud computing's nature } \\
\text { due to low levels of knowledge of cloud computing, in turn, restricts SMEs to } \\
\text { examine the advantages of cloud computing services for their businesses }\end{array}$ \\
\hline
\end{tabular}

Kamarudin, Khalili, Aziz, Kamarudin, Wahab (Exploring of Potential of Cloud Computing for Small and Medium Enterprises) 


\begin{tabular}{|c|c|}
\hline Challenges & Description \\
\hline & $\begin{array}{l}{[18,19,21,25,26,27,29,31]} \\
\text { - In terms of maintaining the business, SMEs are at risk when investing more } \\
\text { in the cloud computing system. Owing to the shortages of staff and costs in } \\
\text { the past, SMEs had some limitations in engaging in technical innovation } \\
{[18,19,26,29]}\end{array}$ \\
\hline $\begin{array}{l}\text { Cloud } \\
\text { computing } \\
\text { technology }\end{array}$ & $\begin{array}{l}\text { - Internet technology is required for the service provided, which often means a } \\
\text { certain safety risk. }[17,25,27] \\
\text { - The algorithm and methods used to manage the cloud computing system are } \\
\text { often unknown for most SMEs }[17,30] \\
\text { - Integrating issues of the cloud computing system with existing SME systems } \\
{[17,20,21,25]} \\
\text { - The inadequate resources for the Internet involves internet connections that } \\
\text { lack speed and internet bandwidth while using the cloud computing system } \\
{[17,22,23,27]} \\
\text { - Technology adoption is still very slow and limited, such as visualisation, } \\
\text { implementation, specifications, interface, and performance expectation from } \\
\text { SMEs }[19,24,25,27,32,33] \\
\text { - None clear and standard guidelines for SMEs from a cloud computing } \\
\text { company }[34,35] \text {. }\end{array}$ \\
\hline SMEs expenses & $\begin{array}{l}\text { - Switching costs require extra funds to manage the cloud system, such as } \\
\text { expert workers in IT to handle the cloud system and government taxes after } \\
\text { implementing the system }[17,26,22,38] \\
\text { - The increased cost of capital expenditure required to manage and maintain } \\
\text { the cloud infrastructure through the annual compulsory subscription and } \\
\text { upgrade of storage space }[17,22,24,26,27]\end{array}$ \\
\hline
\end{tabular}

\section{Cloud Computing Services for SMEs}

Many cloud computing services are available for managing and supporting diverse business activities. Examples include storage and backup, web-based e-mail services, Enterprise Resource Planning, online services software, customer relationship management, business intelligence and analytics, software development and testing tools, computer network, and server rental [20]. The broad range of cloud computing services that SMEs can adopt for their business practices is summarised in Table 3 .

Table 3. The Description of Cloud Computing Services for SMEs

\begin{tabular}{|c|c|}
\hline $\begin{array}{ll}\text { Cloud } & \text { Computing } \\
\text { Services } & \end{array}$ & Description \\
\hline $\begin{array}{l}\text { Human resources and } \\
\text { management }\end{array}$ & $\begin{array}{l}\text { - Human resources and management are closely linked to } \\
\text { administration work. Zenefits, BanbooHR, and Zoho Recruit } \\
\text { software are examples of cloud computing services developed } \\
\text { primarily for SMEs. } \\
\text { - These services aim to manage human resources easily. } \\
\text { - Cloud computing services include human resources, payroll, } \\
\text { employee engagement, compensation management, automated } \\
\text { reminder, predictive notification, and advisory services. } \\
\text { - These cloud services help in screening prospective employees. }\end{array}$ \\
\hline Contract management & $\begin{array}{l}\text { - Cloud computing services for contract management offer unlimited } \\
\text { customisation for contract management service. } \\
\text { - It offers an easy way to establish, administer, and save contracts by } \\
\text { automating and simplifying the process. }\end{array}$ \\
\hline
\end{tabular}

Kamarudin, Khalili, Aziz, Kamarudin, Wahab (Exploring of Potential of Cloud Computing for Small and Medium Enterprises) 


\begin{tabular}{|c|c|}
\hline $\begin{array}{l}\text { Cloud } \\
\text { Services }\end{array}$ & Description \\
\hline & - An example of a service provider is Agiloft. \\
\hline Sales & $\begin{array}{l}\text { - This type of cloud computing service focuses on sales, including } \\
\text { managing customer account management, contact management, } \\
\text { forecasting, and customer demographics. } \\
\text { - Example of cloud computing services is Pipedrive and Bitrix } 24 \text {. }\end{array}$ \\
\hline Accounting & $\begin{array}{l}\text { - Accounting is a business activity that involves the recording activity } \\
\text { of transactions. } \\
\text { - Cloud accounting services provide a low-cost, complete accounting } \\
\text { package for SMEs. } \\
\text { - The features include more organising ways in creating invoices and } \\
\text { quotations, recording sales and payment, and producing financial } \\
\text { reports. } \\
\text { - Cloud computing helps SMEs to track their expenses and income } \\
\text { logging. } \\
\text { - Example: Intuit QuickBooks Online Plus, Xpenditure Small } \\
\text { Business, FreshBooks, and Wave. }\end{array}$ \\
\hline Payroll & $\begin{array}{l}\text { - Users may use cloud computing to generate and manage employee } \\
\text { payment records. } \\
\text { - Example: SurePayroll, Intuit QuickBooks. }\end{array}$ \\
\hline Storage & $\begin{array}{l}\text { - Cloud storage software provides a centralised repository for storing, } \\
\text { synchronising, and retrieving business information, files and objects. } \\
\text { - Example: cloud management software, file-sharing software, backup } \\
\text { software, and IaaS Solution Software. }\end{array}$ \\
\hline Communication & $\begin{array}{l}\text { - Cloud computing enables communication via Cloud Communication } \\
\text { Platform Software. } \\
\text { - Incorporate real-time phone, video, and messaging capabilities into } \\
\text { business applications using Cloud Communication Platforms. } \\
\text { Examples of cloud communication platform software include online } \\
\text { conferencing, telephony, softphone, unified communication, and } \\
\text { cloud PBX software. }\end{array}$ \\
\hline
\end{tabular}

Based on Table 3, cloud computing platforms can enhance the SMEs' capability to process tasks or activities related to Human Resources and Management process, including payroll, employee engagement management, and employee performance evaluation screening. Moreover, the cloud computing platforms for contract management are automated and personalised. This allows SMEs to manage their contracts more effortlessly. Furthermore, SMEs can make their sales more effective and have tighter control of their accounts. Cloud computing services offer a storage-related service where SMEs can store their data at any time from any place with a usable connection. Finally, for collaboration purposes, SMEs should realize the benefits of cloud computing which ensures that the collaboration with other SMEs or agencies is more comfortable. SMEs can select the service they want to use based on their business needs. This allows SMEs to choose cloud computing services based on their budget allocation and individual needs. Overall, cloud computing offers a wide range of services that can support SMEs in strengthening their business activities.

\section{Conclusion}

Cloud computing is not only about network infrastructure technology advancement but a profound transformation in the provision and use of IT. This leads to inevitable changes in SMEs' operation,

\footnotetext{
Kamarudin, Khalili, Aziz, Kamarudin, Wahab (Exploring of Potential of Cloud Computing for Small and Medium Enterprises)
} 
especially in managing business functions such as human resources, sales, accounting, and others. Research on how cloud computing could enhance SMEs' performance, creating a competitive advantage, remaining viable in the age of knowledge economy (information age), and persistent resilience in confronting the current challenges due to the Covid19 pandemic. Further research regarding cloud computing for SMEs should be at the forefront of agendas for policymakers worldwide.

\section{Acknowledgement}

This research was supported by Universiti Putra Malaysia (Research Grant: GP-IPM/2018/9644900).

\section{References}

[1] B. Hajjar, President of the Islamic Development Bank Group: Covid-19 and Micro, Small and Medium Enterprises, Saving the Global Economy from the Pandemic, Retrieved from: $\mathrm{https}$ ://www.isdb.org/news/president-of-the-islamic-development-bank-group-covid-19-andmicro-small-and-medium-enterprises-saving-the-global-economy-from-the-pandemic, 2020.

[2] S.M. Muriithi, "African Small and Medium Enterprises (SMEs) Contributions, Challenges and Solutions," European Journal of Research and Reflection in Management Sciences, vol. 5(1), pp. 36-48, 2017.

[3] D. Assante, M. Castro, I. Hamburg, and Martin, S. "The Use of Cloud Computing in SMEs," Procedia Computer Science, vol. 83, pp. 1207 - 1212, 2016.

[4] Anon, 15 benefits of cloud computing for a small business. Retrieved from: https://www.telappliant.com/blog/15-small-business-cloud-benefits, 2016.

[5] M. Böhm, S. Leimeister, C. Rield and H. Krcmar, Cloud computing and computing evolution. Retrieved from:

http://www.joint-research.org/ wpcontent/uploads/2011/07/BoehmEtA12009c.pdf, 2010.

[6] M. Attaran and J. Woods, "Cloud computing technology: improving small business performance using the Internet," Journal of Small Business and Entrepreneurship, vol. 31(6), pp. 495-519, 2018.

[7] National Institute of Standards and Technology, The NIST Definition of Cloud Computing, Retrieved from: http://csrc.nist.gov/publications/ nistpubs/800-145/SP800-145.pdf, 2011.

[8] T. Diaby and B.B. Rad, "Cloud Computing: A review of the Concepts and Deployment Models," International Journal of Information Technology and Computer Science, vol. 6, pp. 50-58, 2017.

[9] E. Knorr, What is cloud computing? Everything you need to know now. Retrieved from: https://www.infoworld.com/article/2683784/what-is-cloud-computing.html, 2018.

[10] K.H. Salum and M.Z.A. Rozan, "Exploring the Challenge Impacted SMEs to Adopt Cloud ERP," Indian Journal of Science and Technology, vol. 9(45), pp. 1-8, 2016.

[11] L. Modimogale and J.H. Kroeze, "The Role of ICT within Small and Medium Enterprises in Gauteng," Communications of the IBIMA, vol. 1(1), pp. 1-12, 2011.

[12] Microsoft Azure, What is IaaS? Infrastructure as a service. Retrieved from: https://azure.microsoft.com/en-us/overview/what-is-iaas/, 2018,

[13] L. Morais, SaaS - PaaS - CaaS - FaaS: The Solution to Old and New Problems. Retrieved from: https://www.transformingnetwork infrastructure.com/topics/virtualization/articles/439687-saas-paas-caas-faas-solution-old-newproblems.htm, 2018.

[14] A. Saedi and N.A Iahad, "An Integrated Theoretical Framework for Cloud Computing Adoption by Small and Medium-Sized Enterprises," Pacific Asia Conference on Information Systems (PACIS), pp.48, 2013.

[15] S.R. Tehrani and F. Shirazi, "Factors Influencing the Adoption of Cloud Computing by Small and Medium Size Enterprises (SMEs)," in: S. Yamamoto (eds) Human Interface and the Management of Information. Information and Knowledge in Applications and Services, vol 8522. Springer, Cham. 2014. 
[16] H. Hassan, M.H.M. Nasir, N. Khairudin and I. Adon, "Factors Influencing Cloud Computing Adoption in Small and Medium Enterprises," Journal of Information and Communication Technology (1), vol. 16, pp. 21-41, 2017.

[17] K. Kreslins, D. Novik and T. Vasiljeva, "Challenge of Cloud Computing for SMEs: A Case of Baltic Countries," Journal of Innovation Management in Small and Medium Enterprises, vol. 2018, pp. 1-10, 2018.

[18] O.M. Yigitbasioglu, "The role of institutional pressures and top management support in the intention to adopt cloud computing solutions," Journal of Enterprise Information Management, vol. 28 (4), pp. 579-594, 2015.

[19] A. Asiaei and N.Z. Ab. Rahim, "A multifaceted framework for adoption of cloud computing in Malaysian SMEs," Journal of Science and Technology Policy Management, vol. 10 (3), pp. 708-750, 2019.

[20] T. Vasiljeva, S. Shaikhulina and K. Kreslins, "Cloud Computing: Business Perspectives, Benefits and Challenges for Small and Medium Enterprises (Case of Latvia)," Procedia Engineering, vol. 178, pp. 443-451, 2017.

[21] R. Eller, P. Alford, A. Kallmünzer and M. Peters, "Antecedents, consequences, and challenges of small and medium-sized enterprise digitalisation," Journal of Business Research, vol. 112, pp. 119-127, 2020.

[22] S. Abdulrahman and M.K. Salisu, "Investigation of Trends, Benefits and Challenges in the Adoption of Cloud Computing Application in eLearning among Polytechnics in North-East, Nigeria," International Journal of Innovative Science and Research Technology, vol 5 (3), pp. 857-862, 2020.

[23] SS Rupra, "A Descriptive Research on the Security Challenges of Cloud Computing Among Selected SMEs in Kenya," International Journal of Innovative Science and Research Technology, vol. 5 (9), pp. 588-598, 2020.

[24] A. Razzaq, S. Asmai, M. Talib, N. Abdullah and A. Mohammed, "Cloud ERP in Malaysia: Benefits, Challenges, and Opportunities," International Journal of Advanced Trends in Computer Science and Engineering, vol. 9, pp. 7510 - 7516, 2020.

[25] A. Khayer, N. Jahan, M.N. Hossain and M.Y. Hossain, "The adoption of cloud computing in small and medium enterprises: a developing country perspective," VINE Journal of Information and Knowledge Management Systems, 2020, https://doi.org/10.1108/VJIKMS-05-2019-0064

[26] Y.W. Prihatiningtias and M.R. Wardhani, "Understanding the effect of sustained use of cloudbased point of sales on SMEs performance during covid-19 pandemic," The Indonesian Accounting Review, vol 11 (1), pp. 33-46, 2021.

[27] T. Alsafi and I.-S. Fan, "Investigation of Cloud Computing Barriers: A Case Study in Saudi Arabian SMEs," Journal of Information Systems Engineering and Management, vol. 5(4), em0129, pp. 1-8, 2020.

[28] R. Sahandi, A. Alkhalil, and J. Opara-Martins, "Cloud Computing From Smes Perspective: A Survey- Based Investigation,” Journal of Information Technology Management, vol. XXIV (1), pp. 1-12, 2013.

[29] P.K. Senyo, E. Addae and R. Boateng, "Cloud computing research: a review of research themes, frameworks, methods and future research directions," International Journal of Information Management, vol. 38 (1), pp. 128-139, 2018.

[30] N.P. Moens, J.E. Broerse, L. Gast and J.F. Bunders, "A constructive technology assessment approach to ICT planning in developing countries: evaluating the first phase, the roundtable workshop," Information Technology for Development, vol. 16 (1), pp. 34-61, 2010.

[32] S. Marston, Z. Li, S. Bandyopadhyay, J. Zhang and A. Ghalsasi, "Cloud computing - The business perspective," Decision Support Systems, vol. 51(1), pp. 176-189, 2011.

[32] M.G. Aboelmaged, "Predicting e-procurement adoption in a developing country: An empirical integration of technology acceptance model and theory of planned behaviour," Industrial Management and Data Systems, vol. 110(3), pp. 392-414, 2010. 
[33] M. Tarmidi, S.Z.A. Rasid, B. Alrazi and R.A. Roni, "Cloud Computing Awa33reness and Adoption among Accounting Practitioners in Malaysia," Procedia - Social and Behavioral Sciences, vol. 164, pp. 569-574, 2014.

[34] Y.C. Lee, "Adoption intention of cloud computing at the firm level", Journal of Computer Information Systems, pp. 1-12, 2017.

[35] P.K. Senyo, J. Effah, J. and E. Addae, "Preliminary insight into cloud computing adoption in a developing country," Journal of Enterprise Information Management, vol. 29 (4), pp. 505-524, 2016. 